

\section{INDICE}

EDITORIAL PERSONAL ÁMBITOS

Apresentação do monográfico. Abordagem qualitativa: olhares e práticas transdisciplinares nas ciências antropossociais

Presentation of the monograph. Qualitative approach: transdisciplinary views and practices in anthroposocial sciences

Ronaldo Nunes Linhares, António Pedro Costa

MONOGRAFICOS MONOGRAPHS

Identidades femininas na rede: as crianças falam!

Female identities on line: children can speak

Marta Maria Azevedo Queiroz

$12-31$

Transição de cuidados de enfermagem: ISBAR na promoção da segurança dos

doentes - revisão scoping

Transition of nursing care: ISBAR in promoting patient safety - scoping review

Ana Rita Esteves Figueiredo, Teresa Maria Ferreira dos Santos Potra, Pedro Ricardo Martins Bernardes Lucas

$32-48$

Integración de elementos cualitativos y cuantitativos en metodología observacional

Integration of qualitative and quantitative elements in observational methodology

M. Teresa Anguera, Angel Blanco-Villaseñor, José Luis Losada, Pedro Sánchez-Algarra

49-70

Atos educativos com oficines de ecografias: uma investigação otobiográfica

Educational acts at echographie's cineliers: an otobiographic research

Silas Borges Monteiro, Anaise Avila Severo

Actuación de las políticas: política como texto y política como discurso

Action of policies: policy as text and policy as discourse

Mónica Rocío Barón

88-104 


\section{ÁMBITOS PERSONALES PERSONAL ÁMBITOS}

Un retrato de la cultura local a través del Periodismo cultural. Análisis comparado de Sevilla y Porto Alegre

A portrait of the local culture through cultural Journalism. Comparative analysis of Seville and Porto Alegre

\section{ARTÍCULOS ARTICLES}

Microsociología del profesor universitario

Microsociology of an university professor

Antonio Fernández Vicente

La pobreza y el discurso de los mass media. Un estudio de la prensa local argentina

Poverty and mass media 's discourse. A study of the Argentine local press

María del Rosario Sanchez, Silvia London

La comunicación no verbal en las elecciones andaluzas de 2018. Comparativa de Susana Díaz y Teresa Rodríguez en el debate de RTVE

Non-verbal communication in the Andalusian municipal elections of 2018. Comparison of Susana Díaz and Teresa Rodríguez in the electoral RTVE debate

María Hernández Herrarte, Patricia Zamora-Martínez

El infoentretenimiento en la televisión de pago, Movistar+ y el canal \#0.

El uso transmedia de sus contenidos de humor

Infotainment on pay television, Movistar+ and channel \# 0 . The transmedia use of its humorous content

Metodología y formación docente cuestiones claves para la integración de las TIC en la educación

Methodology and teacher training as a key issue for ICTs integration in Education 


\section{RESEÑAS REVIEWS}

Aquelarre. Mujeres en la cultura de masas

Coven. Women in mass culture

Regla Ismaray Cabreja Piedra

216-220

Transición ecosocial y principios éticos en el periodismo: una guía para la comunicación de nuevas narrativas

The Eco-social transition and ethical principles in journalism: a guide for the communication of new narratives

Amanda Salazar Torres

Narrativas ecofeministas y mapa de transición ecosocial para medios de comunicación Eco-feminist narratives and ecosocial transition map for the media 


\title{
Aquelarre. Mujeres en la cultura de masas
}

\author{
Coven. Women in mass culture
}

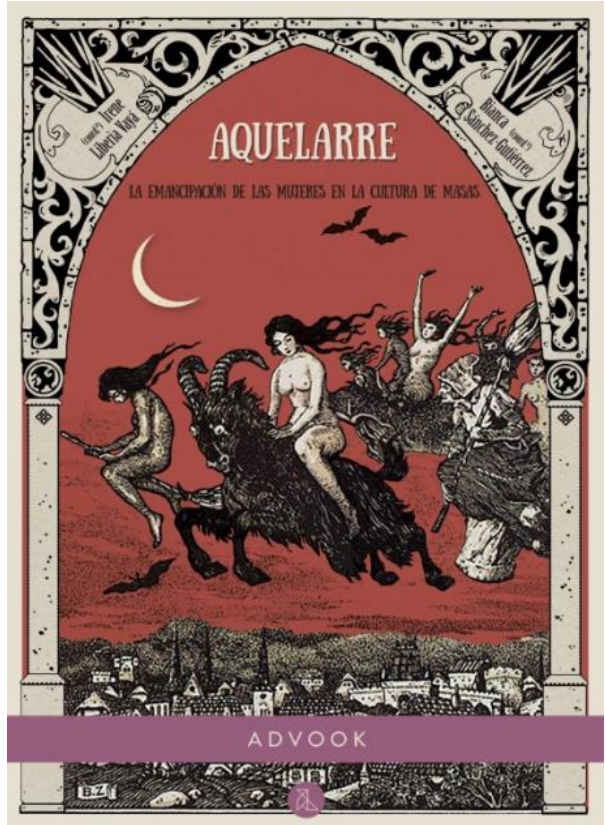

Aquelarre. La emancipación de las mujeres en la cultura de masas

Irene Liberia Vayá

Bianca Sánchez-Gutiérrez

Advook Editorial, Sevilla, 2020

256 páginas

Reseña por Regla Ismaray Cabreja Piedra Universidad de Sevilla, España ismapiedra17@gmail.com

https://orcid.org/0000-0002-5969-3222

DOI:https://dx.doi.org/10.12795/Ambitos.2020.i49.13

La influencia de los medios de comunicación en la cultura de masas ha crecido exponencialmente a través del tiempo. Los efectos de las dinámicas culturales actuales, favorecidos por los procesos que genera la globalización, requieren necesariamente repensar el papel que estos juegan sobre la cultura de masas teniendo en cuenta que transmiten valores y creencias llamadas a consolidar el statu quo establecido. A este análisis no debe desvincularse la necesaria revisión crítica del rol que revisten desde una 
perspectiva feminista, ya que los medios constituyen por excelencia, una de las principales herramientas de las que se vale el sistema patriarcal para legitimarse.

Según Passerini (2003), existen estudios que reflejan que los medios de comunicación como instrumentos de la cultura de masas, se han encargado de privilegiar la realidad masculina. La importancia de no perderle rastro a este problema, sobre todo a la luz de tiempos actuales, hace que el análisis de la influencia de la industria mediática en la reproducción de mitos y estereotipos que legitiman las desigualdades y la violencia de género sea pertinente desde enfoques contextualizados y particularizados a cada uno de los ámbitos de la comunicación. Una mirada oportuna y reciente a este problema la ofrecen Irene Liberia Vayá y Bianca Sánchez Gutiérrez en el libro que juntas coordinan, Aquelarre. La emancipación de las mujeres en la cultura de masas (2020), con el interés de "situar a los medios de comunicación y a la cultura de masas en el contexto de la lucha por la igualdad sexual" (p. 30) y de responder a tres ámbitos de transformación social feminista: la investigación académica, la labor divulgativa y la lucha política.

Todos los trabajos se fundamentan a través de ejemplos concretos y experiencias enfocadas en conflictos particulares, así como también destacan prácticas contrahegemónicas que cuentan los esfuerzos que se han llevado a cabo a favor de la igualdad de género El empleo de distintas metodologías, así como el análisis teórico e histórico que se hace del objeto de estudio en todos los textos, son características que convierten al libro en general en un material completo y riguroso.

La alusión a la larga historia de resistencia que vivieron las mujeres durante la época de "caza de brujas" es uno de los sellos distintivos que pretende rememorar esta compilación a través de su título y las imágenes que lo acompañan, en clara asunción de crítica hacia un período de la historia profundamente marcado por el control sobre los cuerpos de las mujeres. La lectura aporta un pertinente y valioso acercamiento a la comunicación y a la cultura desde una perspectiva de género, así como desde diversos medios y ámbitos concretos de la cultura de masas, tales como: la literatura, el periodismo, la música, la radio, los videojuegos, el cine, la televisión, la publicidad, las redes sociales, etc.

La autoría de cada uno de los diez capítulos del libro está firmada por doce investigadoras que tienen a cargo el desarrollo de textos tras los cuales es evidente notar un detallado y meticuloso proceso de investigación. El primero de ellos es el desarrollado por la catedrática de Filología Italiana, Mercedes Arriaga Flórez, titulado Literatura y Mujeres: querella, genealogías y sororidades. En este, la autora hace un repaso de la literatura española, italiana y francesa, llamando la atención sobre los mecanismos de omisión y exclusión que han caracterizado al sistema literario y que han afectado a las escritoras. A su vez, también pone de relieve las estrategias seguidas por estas mujeres para reafirmarse en el sistema cultural literario. El título del artículo viene a explicarnos en esencia el contenido de esta investigación, enfocada en dar voz sobre las desigualdades entre hombres y mujeres en la literatura, mostrándonos cómo, a través del lenguaje, las mujeres han encontrado canales 
efectivos para trasladar sus experiencias. Se hace un análisis con perspectiva histórica, que muestra cómo todavía en los tiempos actuales hay evidencias de la desigualdad que sigue arrastrando este campo.

El segundo artículo, firmado por Juana Gallego Ayala, Las revistas femeninas en el siglo XXI: de modelo de mujer a mujer catálogo, hace una revisión sobre la transformación de las revistas dirigidas a mujeres entre 2013-2020. Su autora primero reflexiona en las causas del origen de la "prensa femenina", contrastándolo con el hecho de que no ha existido un fenómeno equivalente que se dirija al otro sexo. Este trabajo resulta relevante en la medida en que ofrece una mirada a un sector de crecientes niveles de consumo, señalando el peligro que representan en la reproducción de cánones y estereotipos sobre el "ser mujer" en una sociedad patriarcal que excluye lo diferente. El estudio de caso de la revista Glamour se cita como ejemplo modelo de publicaciones que sellan contradicciones en sus discursos sobre la diversidad, respondiendo a la práctica de mostrar modelos hegemónicos.

El trabajo de María Sánchez-Ramos y Belén Zurbano-Berenguer, Las mujeres en el periodismo. Reflexiones desde, para y por una Comunicación feminista, intenta responder a la cuestión sobre qué papel juegan las mujeres en este sector y reflexiona sobre nuevas formas de hacer periodismo desde un enfoque feminista. Este trabajo brinda cifras actuales que aclaran la todavía desigualdad existente entre hombres y mujeres en cuestiones de ocupación de puestos de alta responsabilidad, salario y dificultades de conciliación de la vida laboral con la familiar. La revista Pikara Magazine es referenciada como una novedosa forma de hacer periodismo de calidad con perspectiva de género.

Por su parte, Silvia Espinosa-Mirabet nos acerca la mirada hacia la radio con el texto $L a$ Radio: una historia en femenino. La autora hace un breve recorrido sobre la presencia de la mujer en el medio, resultando aportadora la presentación de una cronología sobre la evolución de los roles, pasando por ofrecer pistas que argumentan que en este medio, su presencia ha sido muy influida y a veces silenciada. Este artículo vuelve a señalar el problema constante de la desigualdad de género, expresado en la escasa representación de las mujeres en puestos de gestión y de alta responsabilidad.

Teresa López Castilla nos presenta un estudio en donde profundiza en los Accesos de las mujeres a la industria de la música popular, los cuales, la autora encuentra que se ven influidos por una cultura heteropatriarcal hegemónica que crea cada vez más brechas en el camino hacia la igualdad de género, raza y clase. Se desarrolla un estudio de caso centrado en celebrities de gran popularidad, ellas son Madonna y Rosalía. A través de estos ejemplos el texto articula como conclusión la influencia de estas dos figuras populares en la promoción de los valores y estereotipos del patriarcado, sin dejar de reconocer otras lecturas que las señalan como experiencias más autónomas dentro de la cultura hegemónica actual. 
Irene Liberia Vayá presenta el trabajo titulado Mujeres y Cine: creación, investigación y activismo. La lucha por contar, donde realiza una revisión sobre los roles a los que tradicionalmente se ha relegado a las mujeres en la gran pantalla. La autora reflexiona en cómo la teoría y la crítica feminista han trabajado para destapar y desafiar el funcionamiento del discurso fílmico dominante. Se pone como ejemplo concreto algunos de los problemas latentes dentro del cine español, señalando la escasa presencia de mujeres como directoras de producciones fílmicas, así como el bajo presupuesto que por lo general se les asigna cuando están al frente de las mismas. El trabajo invita a la creación de nuevas metodologías de estudios y redes que permitan consolidar el movimiento feminista desde el encuentro y el diálogo.

La televisión y las mujeres: construcción y difusión de estereotipos en el hiperreal, es un trabajo presentado por María Isabel Menéndez Menéndez, en donde se analiza la estereotipia presente en la pantalla televisiva a través de los reality shows. La autora señala que la hibridación, la interactividad y el realismo que provoca son los elementos principales que le han supuesto el éxito a este género en la industria mediática. Se hace alusión a la evolución del concepto de reality y a su creciente proliferación, dado sobre todo por el bajo coste productivo y el alto nivel de audiencia. Resulta novedosa la mirada a este formato televisivo como promotor del sexismo, la violencia simbólica y la constante reproducción de una estrategia centrada en la tiranía de la belleza.

En el artículo La mujer en la publicidad comercial: de la violencia mediática al femvertising, de Bianca Sanchez-Gutiérrez, se analiza la representación de las mujeres en la publicidad, destacando los múltiples estereotipos a los que se han visto expuestas durante décadas. Se hace referencia al femvertising como concepto que debe ser desmitificado como feminista por encontrarse lejos de los propósitos de estas agendas. La mención específica a los peligros de representación variables de acuerdo a la raza, la clase social o la orientación sexual, hacen de este trabajo un estudio que amplifica la mirada para entender que las amenazas de la desigualdad de género en este campo distan de afectar a todas las mujeres por igual.

Eurídice Cabañes Martínez presenta Las mujeres en los videojuegos: horizontes de futuro, en el que se refiere a los videojuegos "como el medio preponderante del siglo XXI" (p. 211) sobre los cuales recae un gran peso para la transformación de la realidad social y política. Una vez más se pone foco en la invisibilidad, la falta de representación y el acoso de que son víctimas las mujeres, esta vez en una industria tan mediada como la de los videojuegos. La autora también se esfuerza por señalar la necesidad en este campo de un modelo de trabajo que subvierta los actuales valores de producción y los modelos de consumo.

Retos, utopías y adversidades del feminismo digital: un territorio en disputa, de Isabel Villegas Simón y Celina Navarro Bosch, analiza cómo las mujeres se han valido de los recursos que les ha ofrecido el ciberespacio, en la lucha por la igualdad y contra el machismo. Constituye un reto el enfrentamiento a las dificultades que impone una red de 
redes controlada por grandes empresas movidas por intereses económicos. Ante este escenario las autoras hacen énfasis en la importancia del feminismo en red, como favorecedor de la creación de comunidades que conectan distintas voces y grupos sociales.

Aquelarre. La emancipación de las mujeres en la cultura de masas ofrece una mirada transversal que polemiza sobre el estado de la desigualdad de género y la situación de las mujeres dentro de las industrias mediáticas y la cultura de masas. Los ejemplos concretos que trae a lugar le aportan una riqueza a la lectura basada en fundamentos propios extraídos de la realidad social y esto provoca interés y enfrenta al lector o a la lectora a un trabajo meticuloso, coherente con el contexto que describe. Lo que también merece la pena señalar es el propio reconocimiento de las coordinadoras del libro de las limitaciones que presenta y uno de ellos fue la imposibilidad de abordar todos los sectores de la industria cultural de masas. No obstante, este elemento no le quita peso a la relevancia de los trabajos que se presentan a lo largo de las 256 páginas que componen el libro. Los análisis desarrollados abren debates pertinentes en la sociedad actual.

\section{Referencias}

Liberia Vayá, I. y Sánchez-Gutiérrez, B. (Coords.) (2020). Aquelarre. La emancipación de las mujeres en la cultura de masas. Sevilla: Advook Editorial.

Passerini, L. (2003). Sociedad de consumo y cultura de masas. En G. Duby, \& M. Perrot, Historia de las mujeres (págs. 388-409). Madrid: Taurus. 